\title{
The Enlightenment of the Development of Foreign University Teachers to the Construction of China's Teachers: From the Perspective of Human Resource Management
}

\author{
Jing Su \\ Department of Human Resource, Jiangsu University, Zhenjiang, P. R. China
}

Email address:

cheer_su@126.com

To cite this article:

Jing Su. The Enlightenment of the Development of Foreign University Teachers to the Construction of China's Teachers: From the

Perspective of Human Resource Management. Science Journal of Education. Vol. 6, No. 1, 2018, pp. 1-7. doi: 10.11648/j.sjedu.20180601.11

Received: August 4, 2017; Accepted: September 12, 2017; Published: January 11, 2018

\begin{abstract}
Faculty development is the key to enhance the core competitiveness of higher education, which is a significant guarantee to effectively implement the strategy of sustainable development and promote the national strength. For nearly 30 years, the operation of university training mechanism has made great contribution to the construction of university teachers, thus cultivating a group of brilliant teachers. However, some problems still remained in faculty development of our country: valuing introduction, despising training; valuing material needs, despising spiritual needs; valuing research, despising teaching; valuing high-end talent, despising comprehensive faculty. These problems largely affect the quality and satisfaction of faculty. Learning from the experience of higher education in developed countries, the building of faculty team in our country can be carried out from the following several aspects: turning the development concept towards humanization, ensuring the development paths to network, converting the development patterns to whole process, changing the management team to professionalization, transforming the evaluation subject to diversification.
\end{abstract}

Keywords: University, Faculty Development, Faculty Team Building

\section{Introduction}

University faculty development is the endogenous mechanism of sustainable development for universities and the key to enhance the core competitiveness of higher education, as well as the strong power to realize Chinese dream of the great rejuvenation of the Chinese nation. The development of teachers can bring benefits to personal development, as well as to students, universities, society and our country. Therefore, we must conduct a development strategy for university teachers to build our country into one with strong higher education.

Faculty development is a foreign concept. Britons generally use staff development in education policy and literature (ab.SD) and American and Japanese adopt faculty development (ab.FD) in education policy and literature. The American Education Association (NEA) published "University faculty development: Enhancing National Power" in 1991 and provides a comprehensive definition of "faculty development": faculty development basically contains four goals: personal development, professional development, teaching development and organizational development. The professional development includes the promotion of personal growth, the enhancement of knowledge, skills and awareness related to professional work. The teaching development includes the preparation of learning materials, the updating of teaching models and curriculum plans. The organizational development focuses on creating an effective organizational climate and promoting the adoption of new teaching practice. The personal development includes conducting the overall plan to improve the interpersonal skills of teachers, maintain health, and determine career goals. The start of Chinese university faculty development research is late. Scholars of higher education research began to pay attention to the development of university teachers since 2001 and research papers began to doubly published in 2005 [1]. In 2006, the fourth international academic conference on higher quality education was held by Xiamen University which was the first discussion on the development of faculty in China. The "International Symposium on Faculty Development" held at 
Northeastern University in 2011 paid specially attention to the improvement of teaching ability. Professor Pan et al gave a broad and narrow definition to the "university teacher development" concept. Broadly speaking, "university teacher development" is that all university teachers continuously enhance their levels in all aspects by way of theoretical studying and practicing. In the narrow sense, the development of university teachers puts more emphasis on the development and improvement of university teachers' teaching ability. According to the level and background of higher education in our country at present, professor Pan et al thinks that the connotation of the development of university teachers should mainly include three aspects: the improvement of academic level, the improvement of teachers' professional knowledge and skills, and the promotion of teachers' morality. Obviously, the development of university teachers should be comprehensive and sustainable development. [2] The educators themselves have comprehensive developments, then universities can cultivate high-quality talent with moral, intellectual, physical and aesthetic development.

\section{The Characteristics of the Development of Foreign University Teachers}

The higher education of foreign countries is relatively mature, and their theories and practical experiences of university teachers' development can be described as an important reference and inspiration for our country. The author takes the United States, Finland and Japan for examples to explore their universality and individuality.

\subsection{The Development of University Teachers in America}

The United States is a world leader in higher education. In 2013 the British "Times Higher Education" published the world university rankings showed that seven American institutions are in the top 10 universities, 46 American institutions in the top 100 universities, and 77 American institutions in the top 200 universities [3]. America has the world's leading higher education. Many universities are famous for offering students with high-quality education services, and high-quality education is inseparable from the perfect theory and practice system built on the development of university teachers [4]. The development of American university teachers dates back to the $1960 \mathrm{~s}$. The University of Michigan Center for Learning and Teaching became the first teachers' development institution in 1962. For half a century, almost every university has established their own university teacher development agencies, and university teachers' development has come into a strong guarantee for the development of higher education in the United States. American university teachers' development has the following characteristics:

(a) Universities are the main body for teachers' development. According to their own conditions, universities design and carry out teacher development projects and activities. Nation and the states do not make specific regulations and guidance documents, so that university teachers' development reflects sufficient academic freedom and academic autonomy. In addition to universities, foundations and service companies participate in the implementation of teacher development activities. They held seminars, training or other forms to promote the theoretical research and practice of university teachers. Moreover, many public or private foundations and social institutions actively provide corresponding financial support for the development of university teachers. Otherwise, the United States do not have a national teacher development administration.

(b) Activities carried out are driven by the demands of teachers and follow the principles that serve the teachers. The development of university teachers is a process of self-development and growth in learning and practice. During this process, the teacher is the subject and the teacher's inner demand is the powerful driving force of its development. The university establishes an independent teachers' development institutions, investigating and evaluating teachers' needs, which do not link to the teacher's appointment, removal, job evaluation or salary, exempt so that teachers are not worried about their jobs.

(c) The object of university teachers' development is very comprehensive, including the new teachers, senior teachers, full-time teachers and part-time teachers, and teachers' development involves the whole process of teachers' professional development. In addition, there are graduates' development programs, which are also called future teachers' preparation projects.

(d) It is a kind of teacher's development activities considering teacher's requirements and people's needs that have rich content and diverse forms. The university teachers development must fully respect the individual development, building a harmonious and active development atmosphere to stimulate teachers' active participation. It is also the reason why the university teacher development activities can be sustained and effective carried out. These activities and projects involve all aspects of teachers' work and life, which can solve practical problems of teachers and can stimulate their intrinsic needs. As a result, many university teachers voluntarily participate in activities and programs provided by the university's faculty development organization [5].

\subsection{The Development of University Faculty in Finland}

Finland is a small Nordic country, but its higher education is well developed. For instance, professor Fan et al studied Helsinki university about the teachers' development department, teachers' development concept, teachers' development projects, assessment measures, incentives and so on, summarizing six major characteristics of the development of Helsinki university and Finland university: (a) The teacher development is included into the school strategic development plan. Helsinki University takes the development of university teachers into the strategic planning of school and the department, and formulate various strategies and plans to protect their implementation. According to the report of 
Helsinki university quality assurance system, the university of Helsinki has established a development plan about the practical knowledge related to different faculty groups in the human resources policy during 2010 to 2012. (b) The teacher development should be closely integrated with university quality assurance. Evaluation of the main body and diversification contents, effective evaluation criteria, timely feedback mechanism, a variety of incentives and other quality assurance measures have become the power and guarantee for the development of university teachers. (c) A complete teacher development network should be built within the university. (d) Incentive measures should be conducted clearly and the development of college teachers should be paid enough attention. (e) Enough attention should be paid to the development of teachers' career in four stages. By introducing a four-stage career development model (doctoral stage, postdoctoral researcher stage, university researchers and university lecturers stage, professors and research leaders stage), teaching and research personnel can get targeted support and promotion at different stages of their careers in the University of Helsinki. (f) The Finnish Education Development Alliance has a role in promoting national teacher development. Since the 90s of last century, the Finnish Education Development Alliance has played a major role in promoting the development of teachers throughout the country [6].

\subsection{The Development of University Teachers in Japan}

Japan is Chinese neighbors, and is the education powerful nation in Asian. In 2014, the British "Times Higher Education Supplement" published the Asian university rankings, and Japan accounted for five in the top 20 well-known Asian universities [7]. In the late 1980s, the concept of university teachers' development was first introduced from American to Japan. Nowadays, the teachers development including theory and practice has been fully spread out in Japanese universities. The university teachers' development has been paid more and more attention, at the same time, it has become more and more institutionalized. In 2007, Japan made a revision to "The university college (Graduate School) setting benchmark" and proposed that the university college (Graduate School) should take the lead in realizing the institutionalization of university teachers. In April of 2008, the "university setting benchmark" made the same modification. The characteristics of universities teachers' development in Japanese are as follows: (a) From the government to the higher education, the problems during the process of localization should be studied as a permanent subject, from the initial imitating to gradually developing a practice model suited to their own national conditions; (b) The macro-control policies can timely promote the development of university teachers to further development. Japanese government (mainly the Japan's science ministry) has played a significant role in driving the development of university teachers. The FD system was took into the new "university setting benchmarks" and extended to the nation, marking the beginning of "FD obligations". (c) Education resources sharing. Establish a communication platform, realize the sharing of educational resources, exchange experiences and find a solution to the problem. (d) The introduction of third-party advisory body. The university council (later incorporated into the central education council) is the advisory agency of higher education, which reviews the basic situation of higher education and provides information and advices to the government. [8]

\section{The Current Construction of University Teachers in China}

Since the 1980s, China has gradually established a three-level training system for university teachers, and has introduced a series of laws and regulations, such as "Pedagogic law of the People's Republic of China", "university teacher training work procedures", "strengthening the construction of teaching staff in colleges and universities", "strengthening the construction of vocational college teachers" and so on, which formed our university training system with Chinese characteristics. Over the past 20 years, Chinese university teacher training system has trained a large number of talents and a large number of key teachers and academic leaders for the institutions of higher learning, so that the quality of college teachers has been significantly improved. However, there are some problems that can not be ignored in the construction of university teachers.

\subsection{The Enrollment Aspect: Valuing Introduction and Despiting Training}

After increasing the enrollment of colleges and universities in 1999, all colleges and universities have begun to pay attention to the introduction of talents, expanding the number of teachers to change the phenomenon of insufficient teachers in universities.

By 2010, there were 134.31 million full-time teachers in the national colleges and universities, an increase of 93.58 million over 1998 , an average of $10.5 \%$ per year. However, there was a shortage in the store of excellent teachers' resources on the whole. Take the author's school for example, about 100 teachers with doctorate are introduced each year, which improves the percentage of teachers with doctoral degree in the teaching staff. In-service education has shown a downward trend (Figure 1). The way of teacher training is still the obtaining of further education, and the other form of training is mainly the short-term training classes arranged by work units, which focuses on teaching and the opportunities are limited. Colleges and universities provide teachers with few opportunities and the form for training is monotonous, so it is difficult to mobilize the enthusiasm of teachers. 


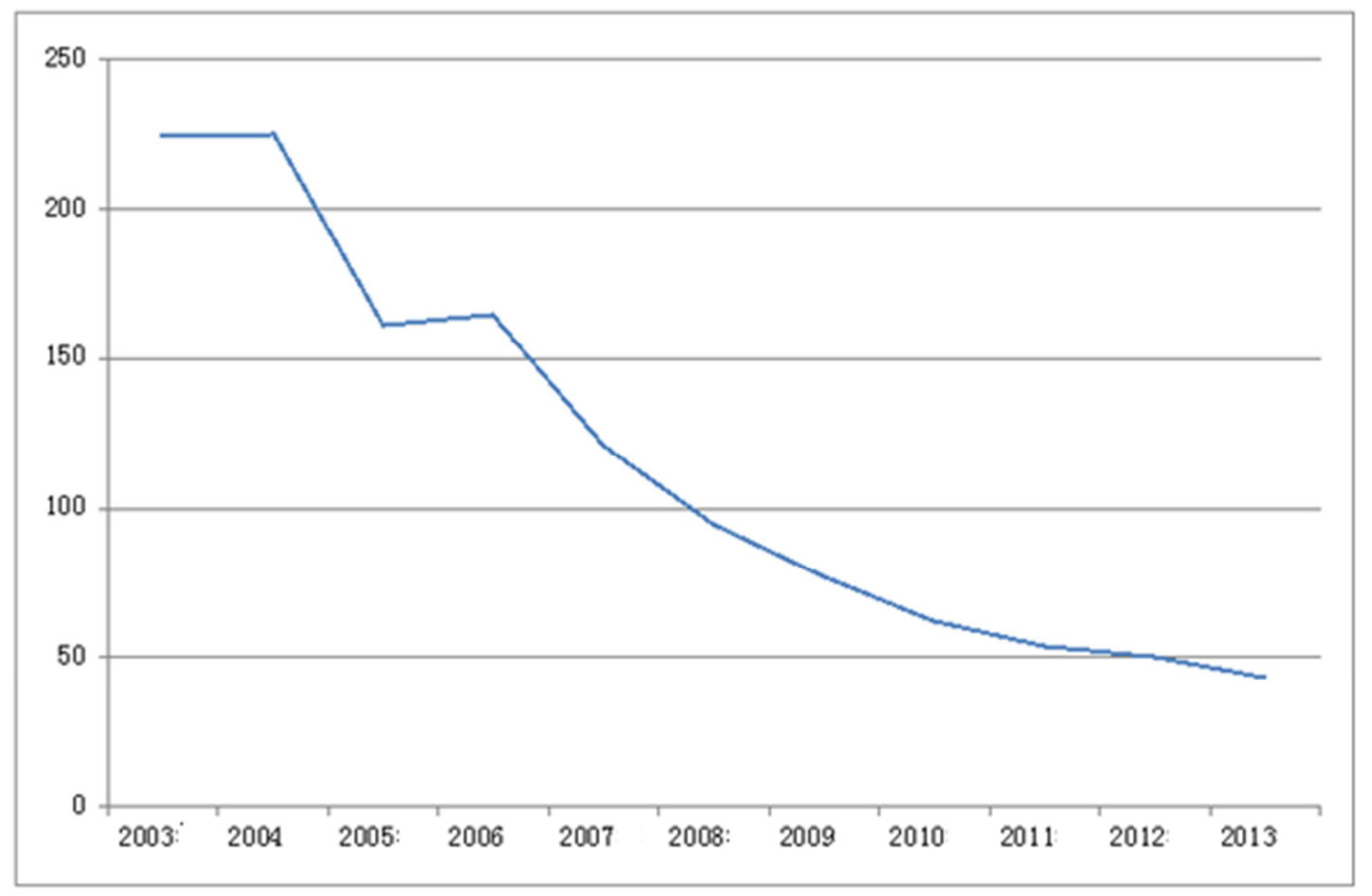

Figure 1. The change of numbers of in-service teachers obtained further education (PhD, Master's) in a school during ten years.

\subsection{The Training Aspect: Valuing Material Needs and Despising Spiritual Needs}

The goal of university teacher training is to achieve the unity of teacher's individual development and organizational development through the combination of professional training and teacher training, the combination of professional training and academic training, the combination of school-based training and off-campus training. At present, the forms of Chinese university teachers training contain domestic visits, senior training classes, young backbone teachers senior training classes, pre-job training, single subjects training, in-service master (doctor) and so on. Training methods are mostly collective class or lectures, occasional discussion. During the process, the lecturers and educator lack adequate emotional communication, and the knowledge or skills learned can only meet the minimum requirements of the job, which can not realize higher requirements, for example, self-realization and personal values. The survey showed that more than half of the respondents were not satisfied with the form and effect of university teacher training, of which $13 \%$ respondents were very dissatisfied and $40 \%$ respondents were dissatisfied (Figure 2) [9]. In addition, the current colleges and universities lack the understanding of the development needs of different groups and different stages of teachers, valuing organizational development, ignoring the needs of individual development (including personal career planning, mental health, the improvement of social communication capacity), which lead university teachers to feel burnout in job. Studies have shown that $80 \%$ of college teachers have emotional exhaustion and $69 \%$ of teachers do not experience career fulfillment. Even some university teachers, especially some inexperienced young teachers, have shown a different degree of burnout (Figure 3) [10]. This situation not only affects the teacher's physical and mental health, but also affects the professional development of teachers, thus affecting the quality of school teaching and student training.

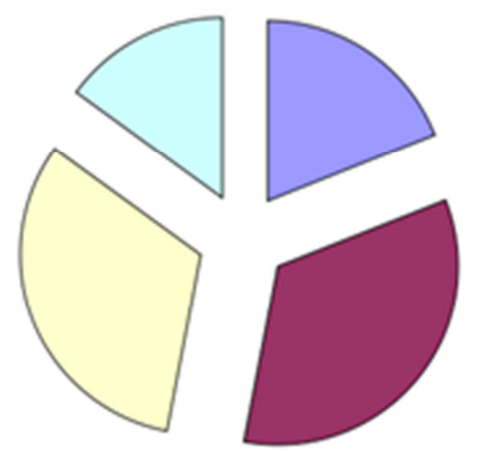

ㅁ. very unhappiness

a unhavoiness

口. happiness

ㅁ. very happiness

Figure 2. The satisfaction of teachers about training form and effect in universities and colleges.
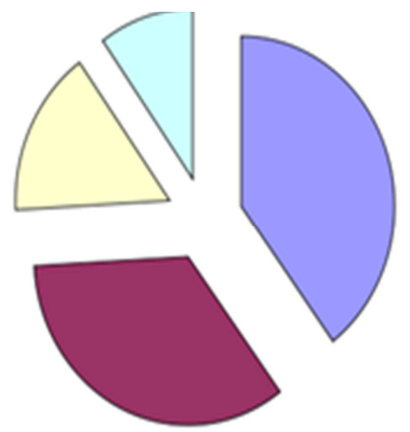

Emotional exhaustion

No sense of achievement Strong sense of achievement

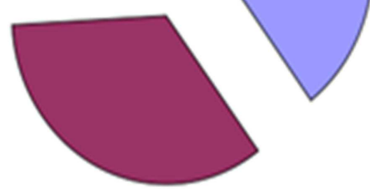

sense of achievement

Figure 3. Occupational burnout of teachers in universities and colleges. 


\subsection{The Promotion Aspect: Valuing Research and Despising Teaching}

"Teacher Law" stipulates that: "teachers are the professionals who perform the responsibility of education and teaching." "Higher Education Law" also points out that: "The task of higher education is to cultivate senior specialized personnel with innovative and practical ability", "University teachers should have the appropriate scientific research ability which can match their positions." The university teachers should have both the appropriate teaching ability and scientific research ability. However, there is a contradictory phenomena in the construction of university teachers. The new teachers in colleges and universities almost have doctoral degree and already have a certain scientific research ability before entering the universities. But most of them were not from normal school, and did not receive the teaching system training. At present, there are only pre-job training and some theoretical aspects of teaching for new teachers in colleges and universities. In the teaching practice, new teachers basically rely on self-exploration or copy their original teaching model. Colleges and universities generally take the "pass with the band" pattern. The old teachers teach the new teachers. However, due to the lack of supervision and incentive mechanism, the effect is ineffective. On the other hand, there is a phenomenon about the appointment of college teachers that teachers attach importance to scientific research, despising teaching. The factors influencing the promotion of university teachers in USA and other countries are job performance, monographs, the number of students, research funds, academic influence and academic group duties, etc., while our influencing factors are education, tenure, research results, level of scientific research, personnel training ability, academic status, relationship between colleagues and so on [11]. When China's universities make policies and evaluation indicators, they often aim to improve the level of education and scientific research. The assessment of teaching is limited to whether teachers have completed corresponding workload and lacks quality assessment of teaching, which results that teachers pay more attention to scientific research and spend less time and effort in teaching.

\subsection{The Incentive Aspect: Valuing High-End Talent and Despising Comprehensive Faculty}

In recent years, the central and local governments have actively promoted the construction of university faculty by increasing investment and arranging major projects, which are mainly embodied in the implementation of the "Thousand Talents Program", "Changjiang Scholars Program", "Innovative Team Development Plan", The training program of higher education, The construction of higher education teaching achievement award, The national high school fine course construction, Huo Yingdong education fund series of incentive plan, strengthening the construction of high-level personnel, and the establishment of high-end talent Team. Incentive measures for college teachers in China with obvious administrative colors are mostly set up by the education authorities, and the award time interval is long and relatively stable, showing a characteristic of "despise assessment, value recruitment".

However, incentive measures are limited to cutting-edge talent and can not motivate more groups. Under the negative influence of peer-to-peer "Matthew effect", young teachers are less rewarded.

\section{Foreign Enlightenment to University Teachers' Development in Our Country}

\subsection{The Transition of Development Concept to the Humanization}

Since 1980s, China has established a national tertiary training system. National and provincial training institutions have the name of "training center", but universities have different titles, such as "Teacher Development Center", "Teaching Development Center", "Teacher Training Center", "Center of Excellence", "Learning Center" and so on. These centers mainly undertake the pre-job training for university teachers, especially young teachers. Obtaining a competency certificate in training is linked with the appointment evaluation, and has administrative color and strong mandatory color. Chinese university teachers' "training concept" obtains popular support, and some researchers still translate teacher development into teacher training in the study of foreign literature. In fact, this is two completely different concepts. "Training" is top-down, relying on administrative orders to allocate places and distribute tasks. Teachers accept the task passively. "Development" takes the teacher's needs as the core, and teachers spontaneously take the initiative to ask for development, reflecting the teacher's wishes. The transition from "training" to "development" is the current trend of the construction of university teachers, and is the embodiment of people-oriented in universities. According to Maslow's theory of demand level development, teachers not only have material, security, survival and other low-level needs, but also have self-esteem, sense of belonging and self-realization and other high-level needs. Therefore, the development of university teachers should change from administrative coercion to self-development, realizing the people-oriented goal, promoting the comprehensive and harmonious development of teachers.

\subsection{The Change of Development Path to "Network"}

The traditional university teacher training mode is one-way, and the mentor is relatively a few fixed people. This method mainly benefits conductors, and the guidance mainly focuses on teaching guidance other than scientific research, management ability, psychological confusion, career planning and other aspects. We should promote the development support network of university teachers, and establish the "multiple - network guidance mode" to realize the aims of multi-support, comprehensive guidance, multi-directional feedback, resource sharing, complementary advantages and win-win cooperation. 
Multidisciplinary-Network guidance model is a new type of learning and training model where teachers learn and share in an equal, cooperative, cross-professional, cross-cultural groups. What's more, network instructors have rich experience and different career stages, and can provide instructional guidance, research services, career guidance, policy advice, emotional support and so on. The mentor and the mentee can achieve timely feedback and benefit from each other. The forms of guidance contain WeChat, microblogs, QQ and other new media to establish guidance for sharing. It can also be carried out in the way of seminars, workshops, quality development and other activities.

\subsection{The Transformation of Development Pattern to "Full Process"}

Learning from teacher development experience of the United States, Finland and other countries, Chinese universities should pay attention to the full development of teachers and build talent development echelon. The construction of university teachers team has the characteristic of long-term and consistency, so the full development of teachers in the construction process should be paid more attention. Teachers with different age, teaching age, education and title also have different development needs. Among them, the development needs of new teachers and young teachers are most urgent. The development of middle-aged teachers becomes the key to the construction of university teachers. Boice considered that if the teachers can achieve success and the satisfaction of the work in early period, it can better maintain stability and efficiency [12]. Therefore, according to the different stages of teacher development, universities should give full support. (a) New teacher. In order to help the new teachers adapt to the new campus environment, culture and system faster and better, the school personnel department together with relevant departments such as the Science and Technology Department, the Academic Affairs Office, the libraries and the trade unions can provide new teachers help based on the application of the new teachers' personal needs. Schools with the thoughtful service help them to achieve the role conversion and to fit into the group as soon as possible. (b) Mid-career teachers. Schools should help teachers to balance work with family responsibilities, establishing academic goals and establishing academic research teams. The school personnel department and the relevant departments give financial support and other support for teachers through a series of talent projects and set up learning projects about time management, teamwork, interpersonal and others to ease the pressure of teachers. (c) Vocational late teachers. The school can arrange excellent teachers to supervise the new teachers and guide teaching practice, which not only meets the new teacher's teaching development needs, but also makes the old teachers get professional satisfaction.

\subsection{The Transformation of Management Team to "Professionalization"}

Management is also the productivity. Scientific, rational and "people-oriented" management is the "soft power" of the school development and is an important way to improve the management level of college education. The personnel works in universities should adapt to the new requirements under the new situation and turn management into service, following the rules of education development and human development, psychological characteristics, doing a good job in human resource development, activating the potential of all teachers and comprehensively improving the level of teachers. At present, the administrative departments of teachers construction in Chinese universities are mainly personnel department and Educational Administration. The management is relatively scattered and managers are mostly "halfway". Universities must establish a professional development management team for teachers with professional development workers for university teachers including project designers and implementers. These professionals should be familiar with the school culture and system, can make suggestions for the development of all aspects of teachers, carry out researches on the development of university teachers, and use theoretical research to guide the practice work. On the one hand, universities should introduce professional education personnel. On the other hand, universities should carry out the teachers' development projects of managers to solve the problem of managerial career development planning and help the existing managers become experts in teacher development, so that they can carry out research on teachers' development needs, developing independently the corresponding teacher development projects, introducing and training a professional teacher development workers team.

\subsection{The Transformation of Evaluation Subject to Diversification}

The complete evaluation system is an important part of the university teachers' construction guarantee system. Chinese current assessment system is not perfect, for example, in the assessment of scientific research, teachers should publish a certain number of papers, and must publish in the designated journals. Assessment system only pays attention to the results and does not attach importance to the process, emphasesing on the quantity instead of quality, paying attention to the participation of training instead of attaching importance to the effect of training in the teachers' training. Colleges and universities in the United States, Finland, Japan and other countries promote development through assessment. I believe that evaluation of Chinese teacher's development should realize the following four points at least: (a) the evaluation criteria should be detailed and feasible. (b) The participants of evaluation include teachers, students and departments. Teaching and research should be placed in the same position, and the evaluation of teaching should emphasis on the whole process of teaching to improve the teacher's attention to teaching work. (c) The purpose of the evaluation is to timely feedback the evaluation results, so that improvements can be quickly conveyed to the evaluation of the object. (d) Evaluation should be carried out regularly, and conduct the follow-up assessment for the improvement of feedback. In 
addition to self-evaluation, universities should also introduce third party consultation and evaluation agencies. These consultation and evaluation institutions can provide development suggestions and project guidance, tracking and evaluating the development projects of universities according to the needs of universities. At present, cooperation between universities and third-party consultation or evaluation agencies should be further developed.

Professor Pan Maoyuan pointed out: "In the situation of the higher education popularization, if we want to improve the level of teachers and ensure the quality of higher education, we must introduce this concept and new ideas about teachers development and establish the corresponding facility development system" [13]. As a big nation in higher education, if China wants to become a power nation of higher education, the improvement of university teachers development is one of the key factors. National long-term education reform and development plan (2010-2020) stressed: "Good teachers are the guarantee of good quality in education... Making efforts build a high quality teachers team with noble morality, excellent skills, reasonable structure and vitality".

\section{Conclusion}

Therefore, the introduction of the advanced concepts of the foreign teachers development from the United States, Finland, Japan and other universities and learning from its successful practical experience will certainly play a positive role in the teacher training system and improve the teachers level in China. In the future, the establishment of teacher development agencies in universities will also become an inevitable trend of development.

\section{References}

[1] Gao Guiyun. The present situation of the development of university teachers in China from 2001 to 2009 and the suggestions for further study [J]. Journal of Higher Education. 2012, $29(2)$.
[2] Pan Maoyuan, Luo Dan. Brief discussion about the development of university teachers in China [J]. Journal of Chinese university teaching. 2007, (1).

[3] The world university rankings in the UK Times higher education supplement in 2013. http://sh.qq.com/a/20130621/014579.htm

[4] Wang Li. The research about the development of university teachers in America: from the perspective of history [D]. k. Shanghai: East China normal University. 2012, 29-31.

[5] Xu Yanyu. The characteristics and inspiration of the development of American college teachers [J]. Higher engineering education research. 2008, (3).

[6] Fan Yihong. The research about the development of the university teachers in Finland: a case study about the University of Helsinki [J]. Journal of Xinjiang normal University. 2012, 33 (5).

[7] The higher education in China is catching up with Japan. http://news.163.com/14/0620/15/9V6NNOCE00014AED.html

[8] Chen Mingxin. From the training of university teachers to the development of university teachers: the policy and academic perspective [D].

[9] Zhong Binlin. The present situation, predicament and countermeasure of the development of university teachers in China [J]. Journal of national education school of administration. 2012, (9).

[10] Du Yi. Investigation on the status of teacher burnout in colleges and universities [J]. Education and vocation. 2012, (10).

[11] Chen Suna. A comparative study on the development system and characteristics of teachers in UK and Chinese universities [D]. Xiamen University, 2009.

[12] Kathleen M. Boyden. The development of new faculty in higher education $[\mathrm{J}]$. Journal of professional nursing. 2000, 16 (2).

[13] National medium and long-term education reform and the office of development plan working group. National medium and long-term plan for education reform and development from 2010 to 2020 [Z]. K. Beijing, 2010. 